\title{
Quando a escola recorre à psicologia: mecanismos de produção, encaminhamento e atendimento à queixa na alfabetização ${ }^{1}$
}

\section{When the school calls on psychology: mechanism of production, routing and service relating to complaints in the literacy process}

\section{Marli Lúcia Tonatto Zibetti*}

Professora da Universidade Federal de Rondônia-UNIR, Rolim de Moura, RO, Brasil

\section{Flora Lima Farias de Souza**}

Acadêmica do Curso de Pedagogia, Universidade Federal de Rondônia-UNIR, Rolim de Moura, RO, Brasil

\section{Kelly Jessie Marques Queiróz**}

Acadêmica do Curso de Pedagogia, Universidade Federal de Rondônia-UNIR, Rolim de Moura, RO, Brasil

\begin{abstract}
RESUMO
Este texto apresenta os resultados de uma pesquisa, desenvolvida em oito escolas públicas da rede estadual de ensino em Rolim de Moura - RO, cujo objetivo foi identificar os mecanismos de produção, encaminhamento e atendimento à queixa escolar de crianças em processo de alfabetização. A pesquisa ouviu, por meio de entrevistas semi-estruturadas, a psicóloga da rede pública de saúde e as orientadoras educacionais das escolas participantes da pesquisa. Também foram analisados documentos encaminhados pelas escolas ao Conselho Tutelar solicitando apoio especializado aos alunos com dificuldades. A análise dos dados indica que, entre as profissionais ouvidas, ainda é bastante forte a crença de que a nãoaprendizagem decorre de problemas familiares ou das próprias crianças. Os resultados da pesquisa permitem afirmar que a busca de soluções para os problemas pedagógicos, fora do âmbito educacional, impede o enfrentamento das verdadeiras causas do insucesso no processo de alfabetização.
\end{abstract}

Palavras-Chave: Queixa escolar, Alfabetização, Aprendizagem

\section{ABSTRACT}

In this work we present the results of a study developed in eight public schools in Rolim de Moura - state of Rondonia, in Northern Brazil. The aim of the research was to identify the mechanism of production, routing and service relating to school complaints when working with literacy. Through interviews we listened to the psychologist of the public health and to eight educational counselors of the schools participating in the project. We also analyzed documents sent by the schools, during the year 2007, to the board of child protection, asking for special support to the children facing 
difficulties in learning. The data analysis reveals that, among the professionals interviewed there is a strong belief that the lack of learning is caused by the family or the children's problems. The results of the research allow us to affirm that the search for solutions out of the educational context avoid educators to face the real cause of failure in the literacy process.

Keywords: School complaint, Literacy, Learning

\section{I ntrodução}

O fracasso escolar tem sido um dos graves problemas enfrentados pelo sistema educacional brasileiro em todos os níveis de ensino, porém com grande incidência nos anos iniciais da escolarização. A aprendizagem da leitura e da escrita tem se constituído para grande parcela da população que frequenta as escolas públicas em nosso país, na primeira barreira a ser superada no processo de escolarização. Mas o que tem sido feito com as crianças que não aprendem a ler e a escrever no período estabelecido pela escola?

Estudos desenvolvidos no âmbito da Psicologia Escolar (PATTO, 1999; COLLARES; MOYSÉS, 1996; MACHADO, 1997; BOCK, 2003; SOUZA, 2005) têm denunciado a cumplicidade entre a educação e a Psicologia quando as escolas recorrem aos serviços psicológicos para resolver problemas de não-aprendizagem.

Este texto volta-se para a temática apresentando os resultados de uma investigação que envolveu oito escolas públicas da rede estadual de ensino em um município de Rondônia, com o objetivo de identificar os mecanismos de produção, encaminhamento e atendimento de crianças em processo de alfabetização aos serviços de Psicologia.

Inicialmente são apresentados alguns estudos sobre a queixa escolar. Em seguida descrevemos os procedimentos adotados para a coleta de dados e, por último, os resultados do estudo são discutidos, tendo por base entrevistas realizadas com profissionais das escolas e do sistema de saúde, bem como documentos de encaminhamento de crianças para atendimento psicológico.

\section{Queixa escolar: concepções e intervenções}

Os números do fracasso escolar no Brasil têm sido discutidos sob diferentes perspectivas teóricas. No âmbito da Psicologia Escolar, os estudos de Maria Helena Souza Patto (1999) inauguraram uma perspectiva crítica de abordagem desse problema, enfatizando a necessidade de uma análise dos mecanismos de exclusão geradores do fracasso no interior das escolas. Mecanismos estes que precisam ser estudados à luz de referenciais teóricos capazes de explicitar as relações existentes entre desigualdades sociais e desigualdades escolares no interior da sociedade capitalista.

Inspirados nos trabalhos de Patto, outros estudos têm se voltado para a compreensão da produção de alunos que-não-aprendem no 
interior das escolas, por meio da análise do processo de encaminhamento desses alunos para os serviços de atendimento médico e/ou psicológico (MOYSÉS, 2001; PROENÇA, 2002). De acordo com as autoras estes encaminhamentos têm sido feitos por meio de uma descrição do "problema apresentado pela criança" no processo de aprendizagem, descrição esta que tem sido denominada de "queixa escolar" (MACHADO, 1997).

Tais queixas, na maioria das práticas psicológicas, segundo Souza (1997), têm sido entendidas como problemas de âmbito emocional os quais aparecem no início da escolarização devido aos desafios decorrentes do momento em que se encontra a criança em seu desenvolvimento.

Em pesquisa realizada em cinco clínicas-escola de prestação de serviços de atendimento psicológico em cursos de graduação em Psicologia na cidade de São Paulo, Souza $(2005$, p. 86) constatou que nos estágios da área clínica, a queixa escolar é atendida como um caso clínico, individual, cujas causas são buscadas a partir de hipóteses centradas em problemas familiares e individuais.

As solicitações de avaliação psicológica feitas pelas escolas são atendidas pelos psicólogos no formato de laudos psicológicos [...]. Em quatro das clínicas pesquisadas, não foram encontradas alternativas de avaliações psicológicas em relação ao processo de escolarização centradas na criança e não apenas em questões emocionais e individuais.

Freller (2004) entrevistou psicólogos que atenderam crianças com dificuldades escolares e analisou os laudos por eles elaborados. A autora constatou que a grande maioria dos profissionais propõe os mesmos procedimentos, tanto de diagnóstico, quanto de tratamento para todas as crianças que procuram atendimento, independente da queixa ou do agente de encaminhamento. "O processo psicodiagnóstico consiste em entrevistas de anamnese com a família, sessões de ludodiagnóstico e aplicações de testes de inteligência e projetivos." (FRELLER, 2004, p. 67).

Para a autora, o desconhecimento por parte de psicólogos da estrutura e funcionamento das escolas públicas no Brasil, juntamente com o preconceito em relação às famílias pobres "são muitas vezes justificados e camuflados por teorias psicológicas que explicam tudo pelos mecanismos intrapsíquicos da criança e pelas relações familiares precoces que os determinam." (p. 68). Desta maneira, ao aceitar as crianças como pacientes, propondo psicodiagnósticos, sem conhecê-las melhor e sem analisar as condições de escolarização dessas crianças, os psicólogos estão compreendendo e atuando de forma limitada.

O trabalho de Marçal e Silva (2006) refere-se a uma pesquisa realizada junto aos psicólogos que atuam na rede pública de Saúde 
Mental em uma cidade do Triângulo Mineiro. A pesquisa constatou um alto índice de solicitações de atendimento de crianças entre cinco e treze anos de idade oriundas das escolas.

Dentre os entrevistados, mais da metade afirma realizar anamnese com a mãe (que é quem normalmente procura o serviço), para verificar se a queixa está relacionada somente à aprendizagem ou se existe algum problema de ordem emocional. Investigam a história de vida da criança, as relações familiares, buscando a existência de causas para a não-aprendizagem. Observam ainda o relacionamento familiar e a forma como a família vê o problema.

\begin{abstract}
Na avaliação da criança com queixa escolar, a análise das entrevistas mostra alguns instrumentos utilizados pelos profissionais: hora lúdica (atividades com brinquedos e brincadeiras), desenho (pede-se que a criança desenhe e conte histórias, faça desenho livre e da família), testes (HTP, CAT e Bender), observação da criança (comportamento, desenvolvimento), observação da relação com a família no atendimento conjunto, observação da leitura e da escrita da criança, observação do caderno. (MARÇAL; SILVA, 2006, s.p.).
\end{abstract}

Ainda segundo a mesma pesquisa, 37,5\% dos profissionais afirmam que no atendimento às crianças com queixa escolar orientam os pais sobre como devem acompanhar as tarefas escolares, sugerem exercícios, conversam sobre a forma como eles lidam com a criança, o estabelecimento de limites ou a falta deles, a superproteção etc.

Entretanto, as relações da criança com os processos de escolarização, com a instituição, com a vivência escolar, não são abordadas na avaliação realizada pelos profissionais nos ambulatórios, indicando que o diagnóstico está centrado no aluno e na família, buscando-se causas individuais que desconsideram a rede de relações que envolvem a questão. Para as autoras “[...] esses procedimentos até podem ser válidos, mas são insuficientes no atendimento da queixa escolar." (MARÇAL; SILVA, 2006, s.p.).

Novas abordagens para o problema, construídas a partir das críticas feitas à atuação da Psicologia no processo educacional, consideram que, nesses casos, "[...] é fundamental que a relação da criança com sua dinâmica escolar seja incluída e feita abordagem que possa ir ao encontro de sua realidade, dirigindo-se o olhar para o que a criança sabe fazer, o que ela consegue realizar [...]." (MARÇAL; SILVA, 2006, s.p.).

Nesta direção, trabalhos como os de Freller et al. (2001), Machado (1997 e 2007) e Souza (2006) têm apontado novas possibilidades para o atendimento da queixa escolar.

Os trabalhos de Freller et al. (2001) e Souza (2006) advertem que um trabalho de orientação à queixa escolar que tenha por objetivo 
superar os mecanismos geradores do não-aprender, precisa considerar a dimensão social. Para isso é preciso entender que a queixa emerge de uma rede de relações cujos participantes são a criança/adolescente, sua escola e sua família. Assim, é necessário conquistar um movimento nessa rede que deve ser buscado por meio da a) obtenção e problematização das versões de cada participante; b) promoção da circulação das informações pertinentes e c) identificação, mobilização e fortalecimento das potências contidas nessa rede.

O trabalho que é desenvolvido junto ao Serviço de Psicologia da Universidade de São Paulo, tem início com o atendimento aos pais, pois ao procurar o serviço de Psicologia, são eles os demandantes. Segundo Souza (2006), quando o pai está presente este fato é valorizado, uma vez que a tendência ainda é o comparecimento apenas da mãe. Solicita-se aos pais, nesta oportunidade, que tragam o material escolar da criança, pois este é considerado rica fonte de informação.

O objetivo deste momento é esclarecer aos pais o tipo de atendimento oferecido pelo serviço; colher a versão deles acerca da queixa; investigar e pensar a demanda buscando soluções; verificar se a queixa é de natureza escolar e se encaixa no tipo de atendimento oferecido. A autora ressalta que este diálogo investigativo não segue um roteiro fechado de questões, mas é orientado pelos princípios teóricos que consideram a dimensão social da produção da queixa. Ou seja, atua-se no sentido de compreender melhor a natureza das dificuldades enfrentadas pelas crianças e em que circunstâncias estas dificuldades aparecem:

\begin{abstract}
Assim, quando os pais dizem que seu filho está malalfabetizado e não quer ir para a escola, nossas perguntas iniciais são feitas no sentido de entender melhor, com maior profundidade, o que querem dizer com isso. Por exemplo: pedimos exemplos e circunstâncias em que essas manifestações da criança ocorrem. Pedimos que os pais nos tragam o histórico do filho na relação com a escola e com a alfabetização, procurando resgatar o momento e circunstâncias em que o desencontro se iniciou e se instalou. (SOUZA, 2006, p. 316).
\end{abstract}

A autora esclarece ainda que, questões relativas à gravidez, amamentação, desenvolvimento psicomotor, relações familiares, nunca são solicitadas logo após a discussão da queixa e só são investigadas quando se fizerem necessárias, para que não se leve a família a pensar que os problemas escolares sejam decorrência de fatores individuais ou familiares.

Esse momento, de preferência, é encaminhado em pequenos grupos, pois os pais são convidados a levantar hipóteses sobre as causas das 
dificuldades e encontrar possíveis soluções, tarefa que é potencializada pelo trabalho coletivo. Segundo a autora, muitas vezes este trabalho inicial é suficiente para encerrar o atendimento, pois se percebe que a criança e/ou seus pais e/ou a escola, aparentemente estão encontrando soluções e há indícios de superação das dificuldades. "Por vezes, esse encontro é suficiente para produzir nos pais uma releitura da situação tal que eles se tranqüilizam quanto à gravidade do que está acontecendo e/ou sentem-se capazes de lidar adequada e suficientemente com isso." (SOUZA, 2006, p.316).

Quando necessário, o segundo passo do trabalho é a realização de encontros com as crianças ou adolescentes para colher a versão deles sobre a queixa, valorizando sua condição de sujeitos das suas próprias histórias. Além disso, busca-se acolher suas necessidades, oportunizando-Ihes ter esperanças, oferecendo acolhimento para seus sofrimentos e dificuldades "de modo que possam encontrar inscrição no universo simbólico e tornem-se pensáveis" e assim contribuam para que as crianças e/ou adolescentes possam manifestar e utilizar suas capacidades e potencialidades afetivas e cognitivas.

Conquistar a produção escolar da criança em atividades com sentido e carregadas de afetividade, num ambiente acolhedor, tem revelado muitos conhecimentos onde escola e pais pensavam que não havia quase nenhum, além de fazer com que a própria criança se aproprie e imprima movimento a capacidades que julgava inexistentes ou com as quais tinha uma relação penosa e envergonhada(SOUZA, 2006, p.317)

Outro passo importante no processo de atendimento defendido pela autora é a interlocução com a instituição escolar que costuma ocorrer em dois momentos: no início do processo, quando é solicitado um pequeno relatório do caso e, no segundo momento, quando é feita uma visita à escola para buscar respostas às questões levantadas pelos dados que o quadro sugere. Nessa interlocução procura-se garantir a presença dos professores, evitando-se a relação apenas com a coordenação pedagógica, situação comum nos casos de encaminhamento psicológico. Também se busca estabelecer uma relação horizontal com os envolvidos na escola procurando evitar uma posição de superioridade da Psicologia sobre a educação, combatendo uma abordagem preconceituosa acerca do trabalho dos professores, a qual não leva em conta as condições precárias em que se desenvolvem as atividades pedagógicas.

Nestes encontros procura-se ouvir a versão da queixa apresentada pelos docentes, levantando indagações que permitem esclarecê-la e pensá-la, buscando perceber e valorizar os recursos e esforços empreendidos na solução do problema. Além disso, segundo a autora, o momento também permite levar informações e sugestões 
capazes de contribuir para o surgimento de novas perspectivas para o trabalho.

Uma entrevista de fechamento do trabalho é agendada com a criança/adolescente e pais separadamente, ou no primeiro momento em separado e, em seguida, em grupo. Uma releitura do caso é construída com base no processo de trabalho desenvolvido, trazendo informações novas e também novas visões e perspectivas, além de avaliar o processo de orientação, seus efeitos e os novos passos a serem dados visando a superação da situação inicial.

Machado (2007) também descreve a produção de novos dispositivos para o atendimento à queixa escolar, com vistas à superação de uma prática preconceituosa e individualizante que tende a culpabilizar a vítima pelo não-aprender.

\begin{abstract}
Plantão Institucional foi o nome que demos a esse dispositivo de atendimento criado para produzir coletivamente desconstruções de saberes instituídos, reflexões das práticas, criação de novas possibilidades para combater a produção das ilusões em muitos trabalhos realizados nas escolas. (MACHADO, 2007, p. 123).
\end{abstract}

Trata-se de um atendimento agendado e realizado no Serviço de Psicologia da Universidade de São Paulo que envolve grupos de profissionais de uma mesma instituição educativa ou de um mesmo grupo. Uma vez por mês, durante cerca de duas horas o grupo discute práticas ocorridas na instituição. "O trabalho é necessariamente feito em grupo. Em cada encontro definimos o que poderia ser discutido no próximo e, algumas vezes, acontecimentos na escola exigem que se alterem os rumos da discussão." (MACHADO, 2007, p. 125).

Diferentemente da atuação descrita por Souza (2006), o trabalho proposto por Machado busca propiciar mudanças no contexto gerador da queixa. Entretanto, as duas proposições assumem uma relação diferente com a educação, ampliando o olhar para todos os envolvidos no processo, potencializando o diálogo e instrumentalizando os sujeitos para que encontrem saídas duradouras e de forma coletiva.

Embora a revisão de estudos sobre o tema aponte para a busca de novas formas de intervenção em relação à queixa escolar, a realidade na qual desenvolvemos nossa investigação indica que as práticas em curso nas escolas públicas estaduais do município pesquisado, continuam contribuindo para a culpabilização das próprias vítimas pelo seu insucesso, conforme demonstram os dados apresentados a seguir. 


\section{A pesquisa}

Com uma abordagem qualitativa, (BOGDAN; BIKLEN, 1994) esta investigação teve como objetivo identificar como é gerada a queixa no interior das escolas e o caminho percorrido pelas crianças e suas famílias na obtenção de atendimento junto ao serviço de Psicologia, além de compreender como esse atendimento é realizado.

A investigação foi desenvolvida junto a oito das dez escolas estaduais do município de Rolim de Moura - RO e os dados foram obtidos por meio de entrevistas com as oito orientadoras educacionais, profissionais responsáveis pelo primeiro atendimento às crianças com "dificuldades" no interior das escolas; com a psicóloga da rede municipal de saúde, para quem são encaminhadas as crianças com queixa escolar e também da análise dos documentos de solicitação de atendimento via Conselho Tutelar.

Este procedimento foi inserido na pesquisa a partir das entrevistas com as orientadoras, pois tomamos conhecimento que devido à demora no atendimento dos casos de queixa escolar encaminhados ao serviço público de saúde, as escolas estavam recorrendo ao Conselho Tutelar para agilizar tal atendimento. Para conhecer o tipo de solicitação feita pelas escolas, analisamos todas as solicitações de atendimento psicológico encaminhadas pelas oito escolas envolvidas na pesquisa durante o ano de 2007.

O município de Rolim de Moura, com cerca de 49 mil habitantes (IBGE, 2001), possui apenas um Conselho Tutelar que, portanto, centraliza todas as ocorrências envolvendo crianças e adolescentes, inclusive de ordem educacional.

Como não há no município serviço de Psicologia nas instituições educativas, são as duas psicólogas do sistema de saúde que atendem às solicitações das escolas. Por um acordo entre as próprias profissionais, os atendimentos às queixas escolares, são realizados no Centro de Saúde pela psicóloga entrevistada por nós, evitando-se que as crianças tenham que agendar consulta no Hospital Municipal, onde atende a outra psicóloga.

\section{Resultados e discussões}

Nesta parte do trabalho discutiremos os resultados da pesquisa que apontam para a manutenção de práticas de produção, encaminhamento e atendimento à queixa, inspiradas em modelos individualizantes e estigmatizantes, que ignoram as análises mais recentes construídas pela literatura de abordagem crítica em Psicologia.

Os resultados apontam ainda para a inserção, nessas práticas, de uma nova instituição - o Conselho Tutelar - que, sob a justificativa de garantir os direitos das crianças e adolescentes, tem atuado no sentido de assegurar-Ihes tais atendimentos, ignorando os resultados que tais medidas estão produzindo entre os atendidos. 
Por meio das entrevistas com as Orientadoras Educacionais constatamos que o processo de produção da queixa, no âmbito da alfabetização, segue o seguinte percurso no cotidiano escolar: as professoras queixam-se das crianças que não fazem a tarefa, daquelas que não comparecem à escola e não acompanham as turmas. As orientadoras buscam a solução dos problemas, conversando individualmente com as crianças e/ou estabelecendo contato com as famílias. A medida mais comum é chamar os pais para uma conversa na escola, na esperança de que os responsáveis ajudem a solucionar o "problema" conforme afirma a Orientadora da escola F. "[...] a gente chama, conversa, orienta. Com a criança não tá dando certo? Chama o pai, pra conversar, vê o que tem por trás disso, de que forma os pais podem estar ajudando a gente né?" Ou como explica a orientadora da Escola D: "Quando tem uma criança com um pouco mais de dificuldade, essa criança é trazida até a mim, na sala onde eu atuo, e lá sim, eu converso um pouco mais com a criança, procuro ver o que está acontecendo [...]. (Orientadora Escola D).

Quando questionadas sobre seu envolvimento com o processo pedagógico percebe-se a ausência de trabalho coletivo envolvendo a equipe gestora no enfrentamento dos problemas de aprendizagem no cotidiano das escolas. As orientadoras afirmam que seu envolvimento com o processo de aprendizagem limita-se aos casos que apresentam dificuldades:

\begin{abstract}
Meu trabalho junto à orientação é acompanhar o desempenho delas [das crianças] quanto à aprendizagem delas. Preencher as fichas: tem fichas que elas [as professoras] preenchem para mim e a partir das fichas eu investigo também como está a criança. Tem a questão do reforço, as crianças que precisam do reforço, eu procuro acompanhar elas também: se elas estão vindo realmente, conversando com os pais sobre a importância deste reforço. Acompanho também as questões das tarefas de casa, quando elas deixam de fazer. Então os professores já me comunicam. Eu chamo os pais e procuro estar conversando com eles da importância de acompanhar a criança. É um problema que a gente enfrenta. Tem um número muito grande de crianças que não estão fazendo a tarefa de casa, porque os pais não acompanham, não olham o trabalho das crianças. (Orientadora Escola B)
\end{abstract}

$\mathrm{Na}$ ausência de psicólogos nas unidades escolares o serviço de orientação tem se caracterizado como um espaço de atendimento individualizado dos problemas surgidos em sala de aula, atendendo em salas específicas e preenchendo fichas. Mesmo quando as queixas referem-se ao comportamento dos alunos, apenas uma orientadora afirma observar as salas de aula. E nenhuma delas faz referência a 
alguma intervenção junto ao processo pedagógico. Verifica-se, portanto, que a busca de solução volta-se para o contexto familiar.

[...] as crianças vêm para a escola elas são muito desatentas... a capacidade de concentração é pequena. Isso faz com que elas tenham dificuldade para acompanhar. Vêm com pouco estímulo de casa $[\ldots]$ se a gente fizer um levantamento em cada sala nós temos inúmeros tipos de família. Não tem ninguém que estimule, acompanhe. Há casos que você chama, chama e não vem ninguém. Crianças que moram com a avó. Crianças indisciplinadas. (Orientadora Escola F).

De acordo com as orientadoras ouvidas, quando as iniciativas de conversar com as crianças e com as famílias, fazendo recomendações de como devem se comportar, ou como os pais podem contribuir para que os filhos e filhas sejam bem sucedidos na escola, não surtem os efeitos esperados, procede-se ao encaminhamento dos casos de queixa ao serviço de Psicologia.

Nós pedimos socorro para a psicóloga que atua no município. [...] a gente faz um relatório dessas crianças, uma relação de nome também dessas crianças, endereço, pais e a gente manda pra ela. [...] eu vou até lá entrego e converso com ela [...] aí é a família que leva. (Orientadora Escola D).

Como o grande número de demandas ao Serviço de Psicologia tem gerado demora no atendimento, as escolas adotaram a sistemática de encaminhar ao Conselho Tutelar o pedido de agendamento da consulta, conforme explica outra entrevistada:

Geralmente a gente entra em contato com o Conselho Tutelar, eles mesmos marcam e ficam responsáveis de marcar, eles tem a oportunidade de marcar uma consulta. Porque aqui no nosso município, infelizmente, a carência é muito grande de psicólogos e eles acabam assumindo o município e adjacências, então é complicado. [...] a gente tem recorrido ao Conselho Tutelar e eles lá conseguem, de alguma forma, um meio pra ficar encaixando esse aluno para um atendimento. (Orientadora Escola E).

Assim, além dos encaminhamentos feitos para o Conselho Tutelar autuar pais de alunos faltosos, ou com problemas de comportamento, as escolas passaram também a solicitar o agendamento de tratamento psicológico. Ao analisar as solicitações encaminhadas pelas escolas envolvidas na pesquisa, durante o ano de 1997 foram encontrados 15 casos que solicitavam atendimento psicológico. A idade das crianças e adolescentes encaminhados oscila entre 7 e 14 anos e a maioria das crianças cursava a 2a série. Das 15 crianças encaminhadas 11 eram meninos e 04 meninas. 
Os processos ${ }^{2}$ são iniciados pelo documento encaminhado pela escola (normalmente um ofício assinado pela orientadora ou diretora da escola) no qual constam as justificativas para o encaminhamento e a solicitação para atendimento psicológico. Também constam dos processos as providências tomadas pelos conselheiros tutelares, alguns pareceres psicológicos, ou informações da psicóloga sobre o andamento do atendimento. Nem todos os processos possuem informações sobre o encerramento do atendimento e alguns são arquivados porque as crianças mudaram de município ou de escola.

Invariavelmente percebemos, nos documentos de encaminhamento, as mesmas justificativas apresentadas pelas orientadoras em suas entrevistas: as escolas eximem-se de responsabilidades por considerarem esgotados seus recursos no atendimento às crianças e solicitam a intervenção do Conselho na solução do problema, seja advertindo as famílias, ou encaminhando os alunos e alunas para atendimento médico e/ou psicológico.

Um dos casos analisados tem início por meio do ofício encaminhado ao Conselho Tutelar requisitando atendimento psicológico à Walcir ${ }^{3}$, de dez anos, estudante da segunda série. Apesar da queixa ser pelo suposto furto de dois lápis em sala de aula, o documento informava ainda que o aluno "foi mordido de cachorro no rosto quando era criança, hoje reclama de dor cabeça. Está começando a furtar objetos na escola. É muito nervoso, e quando fica nervoso dói a cabeça. Está atrasado na escola na $2^{\underline{a}}$ série com 10 anos." Neste caso as medidas adotadas pelo Conselho, conforme anotações no processo do aluno, foram as seguintes: agendamento de atendimento psicológico e solicitação à mãe para que providenciasse uma consulta com o oftalmologista.

No documento encaminhado pela escola, chama a atenção a diversidade de informações que comparecem para explicar a situação do aluno: "mordida de cachorro," "furto", "dores de cabeça", "nervosismo" e "atraso escolar". Ao agregar estes dados ao atraso escolar, a escola justifica o encaminhamento e ao mesmo tempo isenta-se de responsabilidades, pois se o menino não avançou na escolarização conforme deveria, subentende-se que haveria razões individuais para isso.

O aluno Antônio, de oito anos, também da segunda série, foi encaminhado ao conselho para que fosse obtida vaga para atendimento psicológico porque a criança não queria ir para a escola. Segundo o relatório do Conselho os pais assinaram o termo de responsabilidade escolar, porque seu filho é obrigado a permanecer na escola. E o conselheiro conclui: "[...] os pais devem curar esse 'vínculo pegajoso', pois a criança não tem ainda maturidade para saber o que quer e nem de dar ordem aos pais sobre o que devem fazer." (grifos nossos). 
Ao analisarmos os encaminhamentos feitos pelas escolas percebemos referências às famílias das crianças que as desqualificam: famílias sem estrutura, famílias que não acompanham as tarefas escolares, famílias cuja composição não atende ao modelo tradicional de pai, mãe e filhos. Ou, quando a criança conta com o apoio familiar, o "vínculo pegajoso" atrapalha. Estas descrições revelam que as escolas e, no caso do aluno Antônio, o próprio Conselho Tutelar, pautam-se por visões idealizadas de família das quais se espera uma contribuição ao processo de escolarização que nem sempre têm condições de dar. Collares e Moysés (1996, p. 166) nos ajudam a problematizar estas concepções ao afirmarem que:

\begin{abstract}
A escola parece ser uma instituição que só consegue dar conta de sua tarefa primordial - ensinar - se a família colaborar, ajudando os filhos em casa, reforçando o que foi ensinado na escola, sendo um tipo de monitor. O que soa muito estranho, quando se considera o índice de adultos analfabetos ou semi-alfabetizados, portanto pais sem condições de ajudar a escola a ensinar seus filhos. Ao se lembrar que hoje muitas mulheres trabalham fora de casa, inclusive as mulheres dos estratos sociais mais pobres, exatamente as que moram nas periferias e são semianalfabetas, é estranha a maneira como a escola coloca suas interações com a família. Ter pais com condições de participar da educação escolar é um pré-requisito para que a criança aprenda.
\end{abstract}

Nos encaminhamentos torna-se evidente a total isenção de responsabilidades da escola, afirmando-se que essa instituição fez tudo que poderia. Entretanto, poucas vezes este "tudo" é descrito. E quando esta descrição comparece, percebe-se que não está relacionada ao campo pedagógico. As medidas tomadas são "freqüentes conversas com o aluno, família, advertência oral e escrita, encaminhamento ao psicólogo."

Proença (2002, p. 182) propõe que olhemos para os encaminhamentos de maneira a compreender as características das escolas que produzem este tipo de queixa. Para a autora "[...] tais encaminhamentos nos revelam o dia-a-dia da escola, os principais conflitos com que professores e alunos se deparam e que de alguma forma tentam resolver, ou seja, 'os pedidos de ajuda da escola'". Ou seja, as queixas que motivam o encaminhamento das crianças para atendimento psicológico revelam as dificuldades da escola para ensinar essas crianças. Revelam que as escolas não estão conseguindo lidar pedagogicamente com as questões que envolvem a aprendizagem e, ao fracassar nesta tarefa, produzem crianças desinteressadas, distraídas, agressivas.

As queixas indicam ainda uma grande dificuldade nas relações entre a escola e as famílias, pois estas relações são atravessadas por 
inúmeros estereótipos e expectativas que não correspondem às condições reais de existência das famílias cujos filhos freqüentam as escolas públicas.

Segundo informações da Psicóloga entrevistada, ao encaminhar as crianças para atendimento, os relatórios que as acompanham revelam as crenças da escola sobre os problemas geradores da queixa:

[...] às vezes vem um diagnóstico fechado porque eles vão colher um histórico familiar da criança; aí vem filhos de pais separados como se isso justificasse o que a criança está vivendo. Eu imagino que na sala de aula o que aconteça é que os professores passam a se comportar com esta criança como uma criança que tem problema, e é o que acaba acontecendo. (Entrevista com Psicóloga).

O que ocorre em sala de aula, só pode ser "imaginado" pela psicóloga, pois 0 atendimento realizado com as crianças encaminhadas restringe-se à criança e à família. O primeiro passo é uma consulta com a mãe a qual é informada sobre os motivos de sua presença. Em seguida são iniciadas as consultas de atendimento para a realização de diagnóstico.

Para obter informações sobre a queixa a psicóloga afirma chamar as professoras para uma conversa, que raramente comparecem. Então é encaminhada uma solicitação por escrito. "Tem um roteiro, um questionário para a professora. Eu peço para a mãe levar por escrito e ela traz novamente por escrito. É assim: em cada 50 professoras uma vem aqui quando eu solicito, as demais não. Alguns nem respondem o questionário, é bem difícil!"

Como os atendimentos são feitos no serviço de saúde, a psicóloga afirma enfrentar dificuldades com materiais e também em relação ao tempo disponível para cada atendimento.

[...] eu tenho feito diagnóstico em várias sessões. Até isso acaba demorando muito mais que demoraria, porque a demanda é grande, então no [atendimento] particular você teria 45 minutos para uma criança, eu dou conta de fechar um diagnóstico em 4 sessões. No público eu demoro, às vezes 10 sessões, porque o atendimento é de 15 minutos porque eu tenho 10, 12 crianças num período. (Entrevista com Psicóloga).

Após a conclusão do diagnóstico os pais são chamados novamente para ouvir os resultados e informá-los dos encaminhamentos que serão feitos para o problema. Os casos considerados "específicos de aprendizagem" permanecem sob atendimento psicológico, agora com o trabalho de intervenção. Trabalho este que, segundo a psicóloga, fica bastante prejudicado por não possuir material adequado na 
clínica para este tipo de tarefa, uma vez que está vinculada ao sistema de saúde.

Em relação à devolução dos resultados do atendimento à escola a psicóloga informa que encaminha um laudo por solicitação da instituição.

\section{Considerações Finais}

Os resultados apresentados indicam a manutenção da cumplicidade entre Psicologia e Educação, conforme apontou Bock (2003). As crianças que não alcançam os patamares de rendimento estabelecidos pelas escolas para cada etapa da escolarização são consideradas portadoras de algum distúrbio que precisa ser corrigido pelos profissionais da saúde. E ao encaminhá-las para tal atendimento as escolas eximem-se de responsabilidades, pois o "problema" saiu do âmbito escolar e está nas mãos dos órgãos competentes, ou seja, o Conselho Tutelar e o sistema de saúde. E estas duas instâncias, acolhem e respondem às demandas escolares, contribuindo para a manutenção de práticas excludentes e estigmatizantes que não têm contribuído para a superação do fracasso escolar.

Essa situação precisa ser repensada no interior das instituições escolares onde são geradas estas demandas que ultrapassam os muros das escolas e envolvem outras instâncias sociais. Conforme afirma a Orientadora da Escola $X$ "Se a gente encaminha é porque já não sabe mais como trabalhar...". As condições materiais e institucionais de trabalho nas escolas, entre as quais a falta de espaços para formação e construção coletiva de alternativas de enfrentamento do fracasso escolar precisam ser discutidas pelo conjunto dos trabalhadores em educação e também pela sociedade. Não podemos continuar submetendo pais, mães e crianças das escolas públicas ao sofrimento de levar seus filhos e filhas para inúmeras sessões de atendimento psicológico apenas para que possam obter um diagnóstico sobre "a doença" que está impedindo as crianças de aprender.

Por outro lado, quando as escolas acionam o Conselho Tutelar e este atua no sentido de obrigar o poder público a fornecer atendimento psicológico a casos que deveriam ser discutidos no âmbito pedagógico, contribui para que o sistema educacional continue transferindo para outros órgãos a responsabilidade sobre a aprendizagem dessas crianças. A atuação do Conselho, como legítimo defensor dos direitos das crianças e adolescentes, pode voltar-se para o fortalecimento de ações que estimulem mudanças na qualidade do sistema educacional cobrando das autoridades competentes e dos próprios profissionais da educação a articulação de políticas públicas em defesa de uma escola de qualidade. 
Em relação ao trabalho pedagógico as entrevistadas demonstram que há uma divisão de responsabilidades entre os/as diferentes profissionais, supostamente voltadas para o bem estar dos alunos e alunas. Entretanto, o que se percebe é que o trabalho escolar não é pensado coletivamente, não há uma construção conjunta de um projeto pedagógico para atender a uma clientela concreta. As limitações da instituição escolar não são consideradas pela maioria das envolvidas, pois as análises estão sempre centradas nos indivíduos: ora nos alunos e alunas; ora nos professores professoras, ora nos médicos ou psicólogos que não fornecem laudos suficientemente esclarecedores e na maioria das vezes, nas famílias que não cumprem com sua tarefa de assistir, acompanhar e ajudar as crianças em seu processo de escolarização.

Ou seja, a crença de que os problemas de aprendizagem são de ordem individual e que sua superação depende da intervenção médica ou psicológica está tão arraigada que impede que se percebam outras possibilidades de intervenção. E o serviço de Psicologia, ao acolher estas queixas, acaba ratificando esse tipo de atuação, evidenciando que as novas concepções sobre a queixa que revisamos no início deste trabalho, ainda não chegou à realidade pesquisada.

A produção de alternativas para a mudança desse quadro, passa necessariamente pela construção de políticas públicas centradas na melhoria das instituições escolares como um todo e não em segmentos do processo educacional como tem ocorrido com medidas de enfrentamento do fracasso, fragmentadas, e que enfatizam ora a supressão de retenção pela implantação de ciclos ou progressão continuada, ora investimentos em formação de professores, sempre desarticulados dos projetos pedagógicos e da cultura que circula nas instituições.

São necessários investimentos urgentes em espaços de discussão e produção coletiva de soluções para os problemas escolares que tomem como ponto de partida os sujeitos concretos e suas percepções da realidade escolar, estimulando-os a analisar as práticas e resultados do trabalho pedagógico desenvolvido nas escolas e, a partir dessas análises, projetem medidas de enfrentamento que sejam estimuladas e apoiadas pelos órgãos públicos responsáveis pela manutenção da educação.

\section{Referências Bibliográficas}

BOCK, A. M. B. Psicologia da educação: cumplicidade ideológica. In: MEIRA, M. E. M.; ANTUNES, M. A. M. (Org.) Psicologia escolar: teorias críticas. São Paulo: Casa do Psicólogo, 2003. p. 79-103.

BOGDAN, R.; BIKLEN, S. I nvestigação qualitativa em educação: uma introdução à teoria e aos métodos. Porto: Porto Editora 1994. 
COLLARES. C. A. L.; MOYSÉS. M. A. A. Preconceitos no cotidiano escolar: ensino e medicalização. São Paulo: Cortez, 1996.

FRELLER, C. C. Crianças portadoras de queixa escolar: Reflexões sobre o atendimento psicológico. In: MACHADO, A. M e SOUZA, M. P. R. (org.). Psicologia escolar: em busca de novos rumos. São Paulo: Casa do Psicólogo, 2004. p.67-81.

Freller, C. C.; Souza, B. De P.; Angelucci, C. B.; Bonadio, A. N.; Dias, A. C.; Lins, F. R.S.; Macêdo, T. E. C. R. Orientação à queixa escolar, Psicologia em estudo, Maringá, v.6, n.2, p.129-134, jul./dez. 2001. INSTITUTO BRASILEIRO DE GEOGRAFIA E ESTATÍSTICA. Municípios brasileiros - Dados Censo 2001. Disponível em http//www1.ibge.gov.br/cidadesat/default.php. Acesso em: 26 jun. 2007

MACHADO, A. M. Avaliação e fracasso: a produção coletiva da queixa escolar, In: AQUINO, J. G. (org) Erro e fracasso na escola: alternativas teóricas e práticas. São Paulo: Cortez, 1997. p.73-89.

Novos possíveis no encontro da psicologia com a educação. São Paulo: Casa do Psicólogo, 2007.

MARÇAL, V. P. B e SILVA, S. M. C. A queixa escolar nos ambulatórios públicos de saúde mental: práticas e concepções. Psicologia escolar educacional, v.10 n.1 Campinas jun. 2006. Disponível em: $<$ http://pepsic. bvs-

psi.org.br/scielo.php?script=sci_arttext\&pid=S1413-

$85572006000100011 \& \operatorname{lng}=$ pt\&nrm=is > Acesso em: 25 jun. 2008

MOYSÉS, M. A. A. A institucionalização invisível: crianças que não-aprendem-na-escola. Campinas, SP: Mercado das Letras; São Paulo: FAPESP, 2001.

PATTO, M. H. S. A produção do fracasso escolar: histórias de submissão e rebeldia. São Paulo: Casa do Psicólogo, 1999.

PROENÇA, M. Problemas de aprendizagem ou problemas de escolarização? Repensando o cotidiano escolar à luz da perspectiva histórico-crítica. In: OLIVEIRA, M.K.; SOUZA, D.T.R. E REGO, T.C. (Orgs.) Psicologia, educação $e$ as temáticas da vida contemporânea. São Paulo: Moderna, 2002. p.177-195.

SOUZA, B. P. Orientação à queixa escolar considerando a dimensão social. Psicologia: ciência e profissão. v.26 n.2 p. 312-319. Brasília jun. 2006. Disponível em: <pepsic. bvspsi.org. br/scielo. php?script=sci_arttext\&pid=S1414-

98932006000200012\&lng=es\&ñm=is> Acesso em: 25 maio 2008

SOUZA, M. P. R. A queixa escolar e o predomínio de uma visão de mundo. In: MACHADO, A. M e SOUZA, M. P. R. (org.). Psicologia escolar: em busca de novos rumos. São Paulo: Casa do Psicólogo, 1997. p.17-34.

Prontuários revelando os bastidores do atendimento psicológico à queixa escolar. Estilos da clínica. v. X, n. 18, p. 82-107, 2005. Disponível 
psi.org. br/pdf/estic/v10n18/v10n18a08.pdf Acesso em: 25 maio 2008.

\section{Endereço para correspondência}

Marli Lúcia Tonatto Zibetti

Campus de Rolim de Moura, Av. Norte Sul, 7.500, Bairro Nova Morada, CEP 76940000, Rolim de Moura - RO, Brasil

Endereço eletrônico: marlizibetti@yahoo.com.br

Flora Lima Farias de Souza

Campus de Rolim de Moura, Av. Norte Sul, 7.500, Bairro Nova Morada, CEP 76940-

000, Rolim de Moura - RO, Brasil

Endereço eletrônico: folly luly@hotmail.com

Kelly Jessie Marques Queiróz

Campus de Rolim de Moura, Av. Norte Sul, 7.500, Bairro Nova Morada, CEP 76940000, Rolim de Moura - RO, Brasil

Endereço eletrônico: kellyjessierm@gmail.com

Recebido em: 26/08/2009

Aceito para publicação em: 25/02/2010

Acompanhamento do processo editorial: Adriana Benevides Soares

\section{NOTAS}

* Doutora em Psicologia Escolar e do Desenvolvimento Humano

** Bolsista de Iniciação Científica

${ }^{1}$ Pesquisa financiada pelo CNPq

2 Os processos consistem apenas em uma pasta que contém o conjunto de documentos relativos a cada criança, organizados em ordem alfabética. Não há um protocolo de controle de entrada ou andamento dos atendimentos e também não existe um sistema de informatização do trabalho. Portanto, a análise realizada incidiu sobre os pedidos que constavam dos arquivos e não do total da demanda do órgão, uma vez que alguns processos podem ainda estar em andamento e por esse motivo, não constar dos arquivos.

${ }^{3}$ Adotamos nomes fictícios para preservar a identidade das crianças. 